\title{
Who has nature during the pandemic? COVID-19 cases track widespread inequity in nature access across the United States
}

\section{Erica Spotswood ( $\nabla$ ericas@sfei.org)}

San Francisco Estuary Institute https://orcid.org/0000-0002-7787-7180

\section{Matthew Benjamin}

San Francisco Estuary Institute

\section{Lauren Stoneburner}

San Francisco Estuary Institute

\section{Megan Wheeler \\ San Francisco Estuary Institute}

\section{Erin Beller}

Google

\section{Deborah Balk}

Baruch College https://orcid.org/0000-0002-9028-7898

\section{Timon McPhearson}

The New School https://orcid.org/0000-0002-9499-0791

\section{Ming Kuo}

University of Illinois at Urbana Champaign

\section{Robert McDonald}

The Nature Conservancy https://orcid.org/0000-0002-7273-6549

\section{Article}

Keywords: COVID-19, pandemic, nature access

Posted Date: February 9th, 2021

DOl: https://doi.org/10.21203/rs.3.rs-203637/v1

License: (c) (i) This work is licensed under a Creative Commons Attribution 4.0 International License. Read Full License

Version of Record: A version of this preprint was published at Nature Sustainability on October 11th, 2021. See the published version at https://doi.org/10.1038/s41893-021-00781-9. 

Title: Who has nature during the pandemic? COVID-19 cases track widespread inequity in

2 nature access across the United States

3

4 Authors:

5 Erica Spotswood(1), Matthew Benjamin(1), Lauren Stoneburner(1), Megan M. Wheeler(1), Erin

6 Beller(2), Deborah Balk (3), Timon McPhearson(4,5,6), Ming Kuo(7), Robert McDonald(8)

7

8 Author Affiliations:

9 1. San Francisco Estuary Institute, Richmond, CA 94804, USA.

10 2. Real Estate \& Workplace Services Sustainability Team, Google, Mountain View, CA

11 3. CUNY Institute of Demographic Research, City University of New York, New York, NY 12 10010, USA.

13 4. Urban Systems Lab, The New School, New York, NY 10003, USA.

14 5. Cary Institute of Ecosystem Studies, Millbrook, NY, USA

15 6. Stockholm Resilience Centre, Stockholm University, Stockholm, Sweden.

16 7. Department of Psychology, University of Illinois, Champaign, IL 61820.

17 8. The Nature Conservancy, Arlington, VA 22203, and Institute of Demographic Research, 18 City University of New York, New York, NY 10010, USA. 


\section{Abstract}

25 Urban nature can alleviate distress and provide space for safe recreation during the

26 COVID-19 pandemic. However, nature is often less available in low-income and communities of

27 color - the same communities hardest hit by COVID-19. We quantified nature inequality across

28 all urbanized areas in the US and linked nature access to COVID-19 case rates for ZIP Codes in

2917 states. Areas with majority persons of color had both higher case rates and less greenness.

30 Furthermore, when controlling for socio-demographic variables, an increase of 0.1 in

31 Normalized Difference Vegetation Index (NDVI) was associated with a $4.1 \%$ decrease in

32 COVID-19 incidence rates (95\% confidence interval: 0.9-6.8\%). Across the US, block groups

33 with lower-income and majority persons of color are less green and have fewer parks. Thus,

34 communities most impacted by COVID-19 also have the least nature nearby. Given urban nature

35 is associated with both human health and biodiversity, these results have far-reaching

36 implications both during and beyond the pandemic.

\section{Introduction}

39 The COVID-19 pandemic has exposed many existing inequalities in the US. The

40 unprecedented impacts of the COVID-19 pandemic, including upsets to daily life, economic loss,

41 and emotional distress, have fallen disproportionately on low-income populations and

42 communities of color $^{1-4}$. These same groups have also faced greater exposure to COVID-19

43 through high public-contact jobs ${ }^{5}$ that often make social distancing difficult or impossible, and

44 higher rates of cases as a result ${ }^{2,3,6-9}$.

Access to nature is also unequally distributed in the US, with vegetation and parks often

46 less available in low-income neighborhoods and communities of color. Many studies ${ }^{10-15}$ have 
47 shown persistent patterns of inequality in individual cities, groups of cities, and nationwide for

48 Normalized Difference Vegetation Index (NDVI) at the census-tract scale ${ }^{16}$. Thus, the

49 communities most impacted by COVID-19 may have the least access to nature. A negative

50 association between COVID-19 case rate and greenness has been shown with county-level data

51 in the United States $^{17}$, but it is not known whether this effect holds when using finer spatial

52 resolution data, nor whether park access has the same negative association with COVID-19 case

53 rate.

54 Nature has the potential to reduce some of the distress associated with the pandemic by

55 improving mental health and providing safe spaces for socializing, physical activity, and

56 recreation ${ }^{18-20}$. Access to greenness (defined here as the total volume of vegetation in an area,

57 quantified using NDVI) and parks has been tied to physical and mental health, including lower

58 risk of mortality, lower odds of depression, and lower rates of obesity and chronic diseases such

59 as diabetes and cardiovascular disease ${ }^{21-23}$. Thus, inequalities in nature access have the potential

60 to translate into inequities in mental and physical health both during and beyond the pandemic.

61 In this study we document the extent of these two, "stacked" inequalities; that is, that low

62 income and majority people of color (POC) communities have both more COVID-19 cases and

63 less nature. We also explore whether there is an association between access to nature and

64 COVID-19 incidence after accounting for income, race/ethnicity, and other potentially

65 confounding variables. There are multiple mechanisms that could produce such an association.

66 For instance, a lack of access to nature might not only deprive individuals of a much-needed

67 mental health resource but may also actively interfere with the body's ability to fight infection.

68 Contact with nature appears to play an important role in our defenses against viruses though

69 boosting Natural Killer (NK) cells ${ }^{24,25}$. This and other mechanisms could keep a higher 
70 proportion of cases subclinical or asymptomatic in areas with more nature. This would result in a

71 negative correlation between greenness and COVID-19 case rates that persists after accounting

72 for socio-demographic characteristics and other factors that are also likely to be related to both

73 greenness and COVID-19. While other mechanisms could also produce this pattern, a first step is

74 to identify whether such a correlation exists.

75 Here, we quantify nature inequality across all census block groups in urbanized areas in

76 the US and link inequality in nature access to rates of COVID-19 cases for ZIP Codes in 17

77 states. Specifically, we ask: 1) Do low-income and predominantly POC communities have both

78 higher COVID-19 case rates and less nature access (defined here by NDVI and park proximity),

79 2) Is nature access related to COVID-19 case rates after accounting for income, race/ethnicity,

80 and other potentially confounding variables, and 3) Do inequalities in nature access persist when

81 examined at resolutions finer than the census tract? We quantify nature access for both parks and

82 greenness in order to ask whether inequality is systematic across all urbanized areas in the US.

\section{Results}

85 We found that majority POC ZIP Codes had both higher COVID-19 case rates and less

86 greenness (Fig. 1). As of September 30, 2020, majority POC ZIP Codes had nearly twice as

87 many COVID-19 cases per 100,000 people compared to white majority ZIP Codes (Fig. 1). Less

88 green ZIP Codes also had higher rates of COVID-19 cases even after controlling for differences

89 in population density, race/ethnicity, income, time since the first recorded case, age, and state

90 (Fig. 2). In a negative binomial mixed effect model of COVID-19 cases, we found a $4.1 \%$

91 decrease in COVID-19 cases with a 0.1 increase in NDVI (Incidence Rate Ratio 95\% CI: 0.9 -

$926.8 \%$ ). Unlike NDVI, park proximity was not significantly related to COVID-19 case rates when 
93 controlling for other variables (Fig. 2). We also found that when controlling for race/ethnicity,

94 NDVI, and age, other factors including income, population density, and the number of days since

95 the first recorded case were not significantly related to the number of cases. While the virus

96 arrived later in lower-density areas, it also tended to hit a larger fraction of the population

97 (Extended Data Table 1), which could explain why both population density and the time since

98 the first recorded case were poor predictors of COVID-19 case rates during the study period.

99 We also found inequality in nature access at the US scale. Across all urbanized areas,

100 block groups with a majority POC are less green (0.1 lower NDVI on average) and have fewer

101 parks ( 0.5 fewer hectares on average). Similarly, low-income block groups are also less green

102 (0.09 lower NDVI on average) and have fewer parks (3.6 fewer ha on average, Fig. 3, Extended

103 Data Table 2). For context, a 0.1 magnitude difference in NDVI is roughly equivalent to a one

104 standard deviation (SD) difference in greenness in our sample: the SD in NDVI across all block

105 groups is 0.15 , and the average within-city SD is 0.08 . In simultaneous autoregressive models

106 (SAR) that account for spatial autocorrelation, the proportion white people in a block group and

107 median household income were both significant predictors of NDVI and park proximity

108 (Extended Data Fig. 1). Similarly, statistically significant differences in access to nature remain

109 after accounting for population density (in both models of park proximity and greenness) and

110 aridity (in the model of greenness).

112 Discussion

113 Taken together, our results demonstrate that COVID-19 has inflicted the greatest burden

114 on communities that also face widespread inequity in nature access. These results have

115 potentially important implications for how communities and individuals manage mental health 
116 and social interactions during a pandemic where socializing, recreation, and physical activity

117 with others are most safely conducted in outdoor spaces.

118 We found an association between greenness and COVID-19 case rates after accounting

119 for income, race/ethnicity, and other confounding factors. While observational data such as ours

120 cannot speak to causal relationships, previous findings from the literature suggest possible

121 mechanisms that could explain this statistical association. Greenness might affect COVID-19

122 case rates if it helps the body fight the virus once exposed, keeping a higher proportion of cases

123 subclinical or asymptomatic. Natural Killer (NK) cells play a key role in the body's defense

124 against viral infections, seeking out and attacking or "clearing" virus-infected cells ${ }^{24,25}$. Contact

125 with nature appears to play an important role in boosting our NK defenses: two two-hour forest

126 walks on consecutive days increase the number and activity of anti-cancer NK cells by 50 and

$12756 \%$, respectively, and activity remained significantly boosted even a month after returning to

128 urban life-23\% higher than before the walks; by contrast, urban walks had no such effect ${ }^{26}$.

129 Another possible explanation for the nature-COVID-19 association is that having less green in a

130 neighborhood makes it more difficult to safely socialize in outdoor spaces. While either, both, or

131 none of these explanations might underlie the lower rates of COVID-19 in areas with greater

132 access to nature, this finding raises the possibility that populations that lack ready access to

133 nature during the pandemic may not only be deprived of a much needed mental health resource

134 but may also be at greater risk of contracting COVID-19. Further research using patient-level

135 data is needed to uncover the mechanistic drivers behind the patterns we show in this work.

136 We found widespread evidence of inequality in access to nature across urbanized areas in

137 the US. These results may have cascading impacts, given nature in urban settings has been

138 associated with many human health benefits while also supporting other ecosystem services and 
139 biodiversity $21,22,27-29$. These patterns are consistent with other studies that have shown inequality

140 in access to parks and greenness ${ }^{10,13,15,16,30,31}$, and here, we show nature inequality patterns at a

141 finer resolution than has been shown previously in the US. Placing our results in context, a

142 difference of 0.1 increments of NDVI has been linked in other research to specific health

143 impacts. For example, living with 0.1 increments lower NDVI around the home has been linked

144 to $12 \%$ higher all-cause mortality ${ }^{32}, 20.6 \mathrm{~g}$ lower birth weight in infants and higher likelihood of 145 preterm birth $^{33}, 10 \%$ higher odds of poor self-reported health, lower neighborhood satisfaction

146 and social capital ${ }^{34}$, and a $39 \%$ decrease in odds of moderately vigorous physical activity in

147 children $^{35}$. Similarly, the area of available greenspace has also been linked to health; pregnant

148 women living in neighborhoods without a greenspace larger than 0.5 ha within $300 \mathrm{~m}$ are $13 \%$

149 more likely to report depressive symptoms ${ }^{36}$, and living closer to larger parks or more total area 150 of parks has been associated with less stress $^{37}$, more physical activity ${ }^{38}$, and lower odds cardio151 metabolic disease ${ }^{39}$. These results suggest that differences in access to greenness and parks of a 152 similar magnitude as shown here have the potential to impact a range of physical and mental 153 health outcomes for low-income populations and communities of color.

154 We show that the pandemic has compounded the disadvantages in low-income areas and 155 communities of color already facing fewer acres of park available for recreation and less

156 greenness. Our results suggest that inequity in nature access has potential public health 157 implications during a period of profound social and economic upheaval and mental health 158 distress. In the short term, actions to overcome barriers to nature access during the pandemic, 159 such as keeping urban parks in low-income neighborhoods and communities of color open, safe, 160 and accessible could help to relieve some of the distress associated with the pandemic. Over the 
161 longer term, actions taken to redress inequity through park creation and greening interventions 162 could have substantial broader public health value beyond the pandemic.

\section{Methods}

165 We combined spatially explicit data on nature access, socio-demographic characteristics, 166 and COVID-19 case rates. We conducted two separate analyses at separate spatial scales, both 167 limited to urban areas. In the first, we combined COVID-19 data with nature access and socio168 demographic data at the ZIP Code scale across 17 states to ask whether communities with the 169 highest COVID-19 case rates also have less access to nature. In the second analysis, we related 170 nature access with socio-demographic data across all 486 Urbanized Areas in the US at the block 171 group scale to explore US-wide patterns of nature inequality.

173 Data. Study extent. For the COVID-19 analysis, the availability of fine-scale case data limited 174 the study sites to 17 states that provide publicly accessible state-wide data at the ZIP Code scale. 175 While individual counties also publish COVID-19 case data at the ZIP Code scale, the timelines, 176 systems, and formats for reporting and publishing these data are variable and inconsistent, and 177 reconciling these differences were beyond the scope of this analysis. We limited our analysis to 178 the ZIP Code scale because the alternative county scale is large enough to contain significant 179 heterogeneity in both greenness and socio-demographic characteristics which could obscure 180 relationships among these variables. We limited our analyses to ZIP Codes that contain centroids 181 (i.e., geographic center) within either Urbanized Areas (greater than 50,000 people) or Urban 182 Clusters (greater than 20,000 people) as defined by the US Census Bureau. We also removed 66 
ZIP Codes with a median age value of 0 , as well as 382 Zip Codes with a median income value

184 of 0 . The remaining dataset contained 2,652 urban ZIP Codes across the 17 states in our analysis. urbanized areas (excluding urban clusters) in the US (excluding Puerto Rico), including 142,325 block groups and 5,197 incorporated cities. Each state was represented by at least one urban area.

COVID-19 data. We compiled publicly available COVID-19 case data at the ZIP Code scale

190 from individual state department of health websites on October 1, 2020, including data up to 191 between September 1 and 30, 2020 for all states (Extended Data Table 1). We considered only 192 reported cases of COVID-19 in the earlier phases of the pandemic (March through September), 193 because some states, such as New Jersey, ceased to update their websites with new ZIP Code194 scale data beyond September. We were not able to obtain locally specific data quantifying the 195 variation in rates of testing among different demographic groups. Evidence from some states 196 (e.g., Illinois, see Extended Data Table 1) suggests that minority groups were being tested at 197 much lower rates than whites, particularly in the early phases of the pandemic. These data would 198 likely have strengthened our results, since we found that POC majority ZIP Codes have both 199 higher case rates and less greenness.

200 We compared COVID-19 case rates to nature access and socio-demographic variables 201 using data described below. We calculated case rates as the cumulative number of cases per 202100,000 people for each ZIP Code using the total population for each ZIP Code Tabulation Area 203 (ZCTA) from the American Community Survey (ACS) 2018. ZCTAs were designed to represent 204 ZIP Code routes as two dimensional areas, and while there are minor discrepancies in some 205 places, they are not common in the urban areas included in this analysis ${ }^{40}$. We also calculated the 
206 total days since the first recorded case (available only at the county scale) for each ZIP Code,

207 using data from the New York Times US Coronavirus Database ${ }^{41}$.

208

209 Nature access data. To quantify inequality in nature access, we used to metrics to quantify

210 nature access: the amount of greenness and proximity to parks. We calculated these two metrics

211 at the level of US Census block groups for nature inequity analyses and ZIP Codes for COVID-

21219 analyses. Greenness was quantified using NDVI, which measures the reflectance of green

213 vegetation, and is linked to the amount, health, and leaf characteristics of vegetation, with

214 unitless values that vary from -1 to 1 . Values between 0.2 and 1 vary from sparse to heavily

215 vegetated, and values close to or below zero represent other types of land cover such as

216 impervious cover, water, clouds, or snow. Average NDVI values were calculated across each

217 block group (nature equity analysis) or ZIP Code Tabulation Area (ZCTA) (COVID-19

218 analysis). NDVI data was derived from Landsat imagery and processed using Google Earth

219 Engine, filtering images from 1/1/2017 to 12/31/2018 to correspond most closely to the time

220 period in which socio-economic and demographic data was collected. In order to account for

221 broad geographic patterns in NDVI, which varies at regional scales based on climate and aridity,

222 we included the Global Aridity Index in our model for NDVI inequity. This publicly available

223 dataset represents the ratio between precipitation and vegetation water demand, where higher

224 values represent more humid conditions ${ }^{42}$.

225 To measure park proximity, we generated a database of publicly accessible parks in the

226 US that is as comprehensive as possible by combining four publicly available nationwide

227 datasets. These datasets together included 337,441 parks across the entire US, 143,228 of which

228 are contained within the 486 urbanized areas in the US (Trust for Public Land ParkServe, US 
229 Protected Areas Database, National Conservation Easement Database, and ESRI Parks, see

230 Extended Data Table 4). We did not exclude parks below a size threshold, nor did we filter parks

231 based on characteristics such as amount of greenness or recreation type. Therefore, our dataset

232 includes small municipal parks that may have relatively little nature if their primary function is

233 to provide sports facilities such as basketball courts, playgrounds, or other types of recreation

234 that typically require large impervious surfaces.

235 Park proximity was calculated as the total acres of park within 1,000 $\mathrm{m}$ of the centroid of

236 census blocks. This distance corresponds roughly to a 10 minute walk, a common metric used by

237 parks advocates and for measuring park accessibility ${ }^{43,44}$. For both ZIP Codes and block groups,

238 population-weighted averages were taken of block-level park proximity to derive a park

239 proximity value for each ZIP Code and block group. These population-weighted estimates were

240 calculated to reduce the effect of areas with high park proximity where very few people live.

242 Socio-demographic data. Socio-economic and demographic data were obtained from the US

243 Census Bureau 2014-2018 American Community Survey 5-year estimates ${ }^{45}$, which summarize

244 data collected from 1/1/2014 to 12/31/2018. These data were collected for all block groups with

245 their centroid within US urbanized areas (nature inequality analysis) and for Zip Code

246 Tabulation Areas (ZCTA) within the 17 states that report COVID-19 data at the ZIP Code scale

247 (COVID-19 analysis). Variables included median household income, the number of white people

248 in a block group or ZCTA, median age, and total population (used to derive population density, 249 and the proportion POC in the block group or ZCTA). 
251 Statistical analyses. We conducted two analyses at different spatial scales. In the first, we 252 analyzed COVID-19 rates using data from 17 states at the ZIP Code scale using a negative

253 binomial generalized linear mixed effects model. In the second, we quantified nature inequality

254 in all urbanized areas in the US at the block group scale. This analysis used SAR models to relate 255 NDVI and park proximity to socio-demographic factors. All analyses were performed in R 256 (version 4.02$)^{46}$. SARs were performed using the package $\operatorname{spdep}^{47}$, and negative binomial mixed 257 effects models were performed using the package $\operatorname{lme} 4^{48}$.

259 COVID-19. We analyzed COVID-19 case rates by ZIP Code using a negative binomial 260 generalized linear mixed effects model, after verifying the absence of significant spatial 261 autocorrelation using the Moran's $I$ statistic $^{49}$. A single full model related COVID-19 case rates 262 in each ZIP Code to fixed effects for NDVI, park proximity, the proportion white people, median 263 income, population density, median age, and the total number of days since the first recorded 264 case (county-scale). We included state as a random effect to account for the non-independence of 265 data from the same state that could occur as a result of processes we are not capturing with 266 available data, such as differences in the timing of public policy responses such as lockdowns or 267 mask mandates ${ }^{49}$. All explanatory variables were centered and scaled. To estimate the impact of 268 a 0.1 increment change in NDVI, We fit an additional model using unscaled NDVI multiplied by 26910 (all other variables scaled) in order to calculate the Incidence Rate Ratio (IRR), or 270 exponentiated effect estimates and their $95 \%$ confidence intervals, to determine how a 0.1 271 increment of change in NDVI affects COVID-19 ${\text { case } \operatorname{rates}^{50} .}^{5}$ 
273 Nature inequality. To evaluate the relationship between nature access and socio-demographic

274 variables, we built two models and analyzed park proximity and NDVI separately. Both models

275 included median income, the proportion white people, and the population density in the block

276 group as covariates, and the aridity index was also included in the NDVI model. We evaluated

277 whether spatial autocorrelation was present using the regression residuals from an ordinary least

278 squares model using the Moran's I statistic. At the block group scale, models for NDVI (Moran's

$279 I=0.64$, P Value $<0.001$ ) and park proximity (Moran's $I=0.62$, P Value $<0.001$ ) models both

280 contained evidence of significant spatial autocorrelation. To address this issue, we used SAR

281 error models, which include a spatial error term defined from a neighborhood matrix and

282 autocorrelation in the dependent variable ${ }^{51}$. These models assume the autoregressive process is

283 found only in the error term, such as when spatial autocorrelation is not fully explained by the

284 included explanatory variables ${ }^{52}$.

285

286 Acknowledgements

287

288 We thank the Google Ecology Program for funding this work and support for ENS, MB, LS,

289 MMW, and RM. We also thank Kelly Iknayan, Robin Grossinger, Letitia Grenier, and Micaela

290 Bazo for thoughtful comments and Pablo Herreros-Cantis for data support. TM is supported by

291 the US National Science Foundation (awards \#1444755, \#1927167, \#1934933, and \#2029918).

292 MK is supported by the USDA National Institute of Food and Agriculture, McIntire Stennis

293 project ILLU-875-972. Any opinions, findings, conclusions, or recommendations expressed in

294 this publication are those of the author(s) and do not necessarily reflect the view of the U.S.

295 Department of Agriculture. 


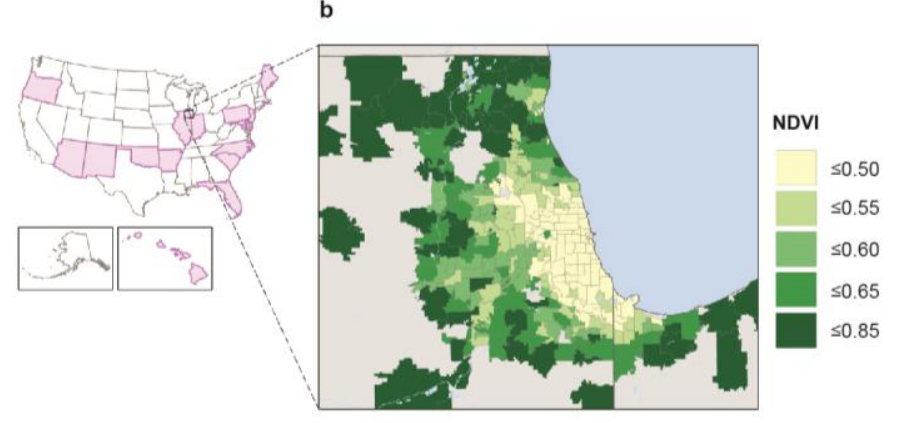

d

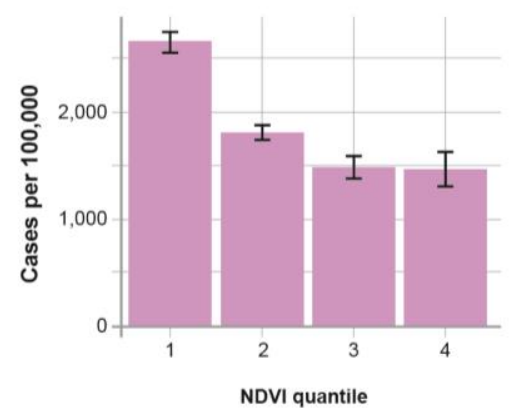

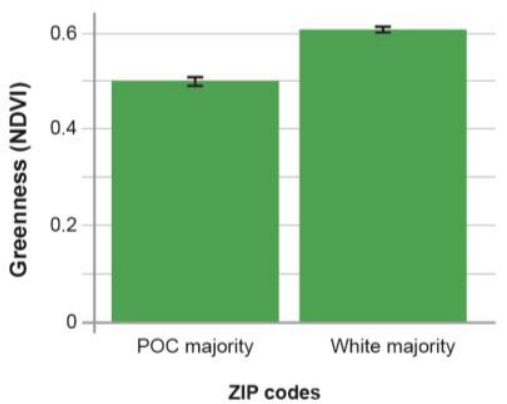

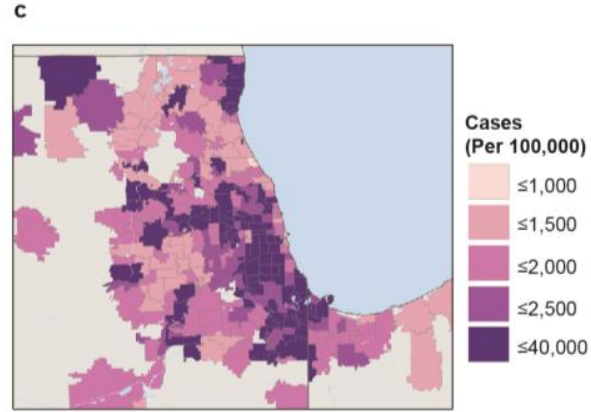

f

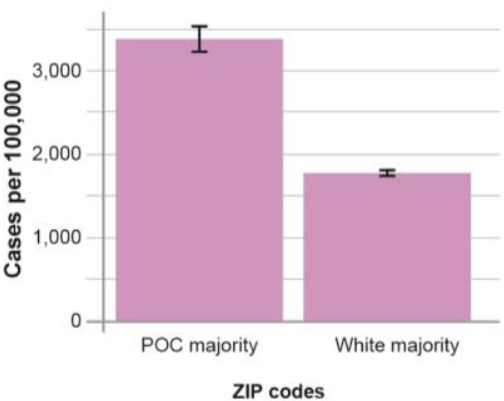

301 Fig. 1 | COVID-19 case rates are related to both greenness and race/ethnicity. a, This

302 analysis used reported COVID-19 cases at the ZIP Code scale from 17 states. b, Average NDVI

303 values and $\mathbf{c}$, COVID-19 case rates per 100,000 people across ZIP Codes around Chicago, IL, as

304 an example. d, Barchart of greenness (NDVI) represented as quantiles and rates of COVID-19

305 showing a decline in cases with higher NDVI. e, Barchart of greenness showing higher greenness

306 in white majority ZIP Codes. f, COVID-19 case rates (per 100,000) showing lower rates of cases

307 in majority white ZIP codes. Error bars represent approximate 95\% confidence intervals. 


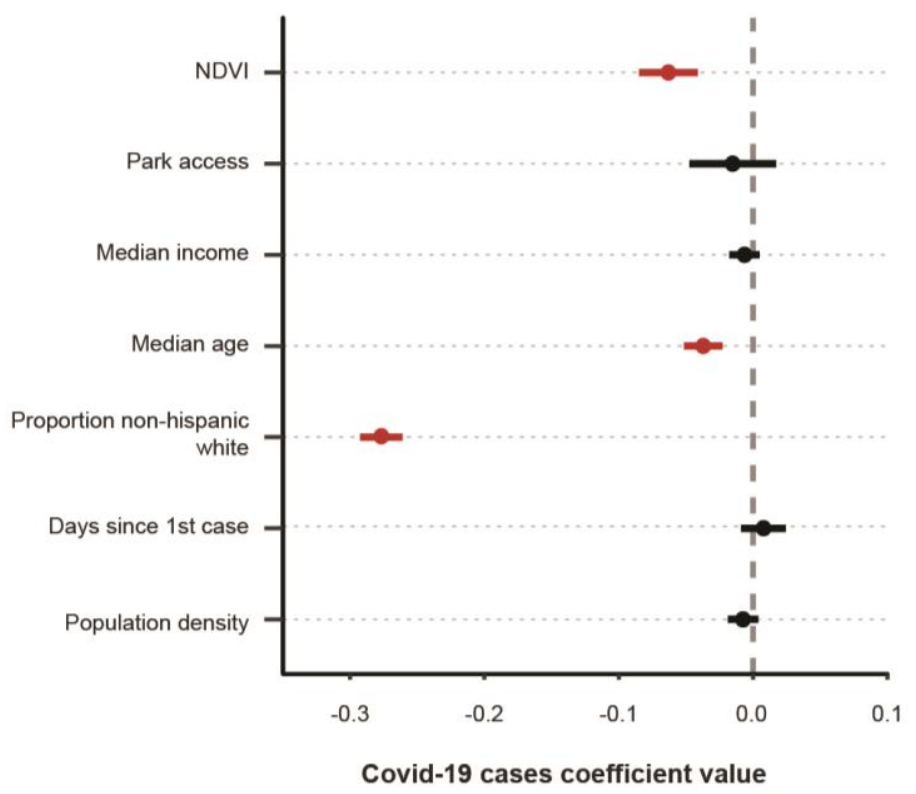

311 Fig. 2 | Greener ZIP Codes have fewer COVID-19 cases after accounting for other factors.

312 Coefficient values represent effect sizes from a negative binomial mixed effects model for the 313 relationship between rates of COVID-19 (cases/100,000 people) and greenness (NDVI), park 314 access (ha), median income, median age, proportion persons of color, days since the first case 315 (county-scale), and population density. Coefficient values are represented as dots, bars represent $31695 \%$ confidence intervals, and significant variables are shown in red. 
a

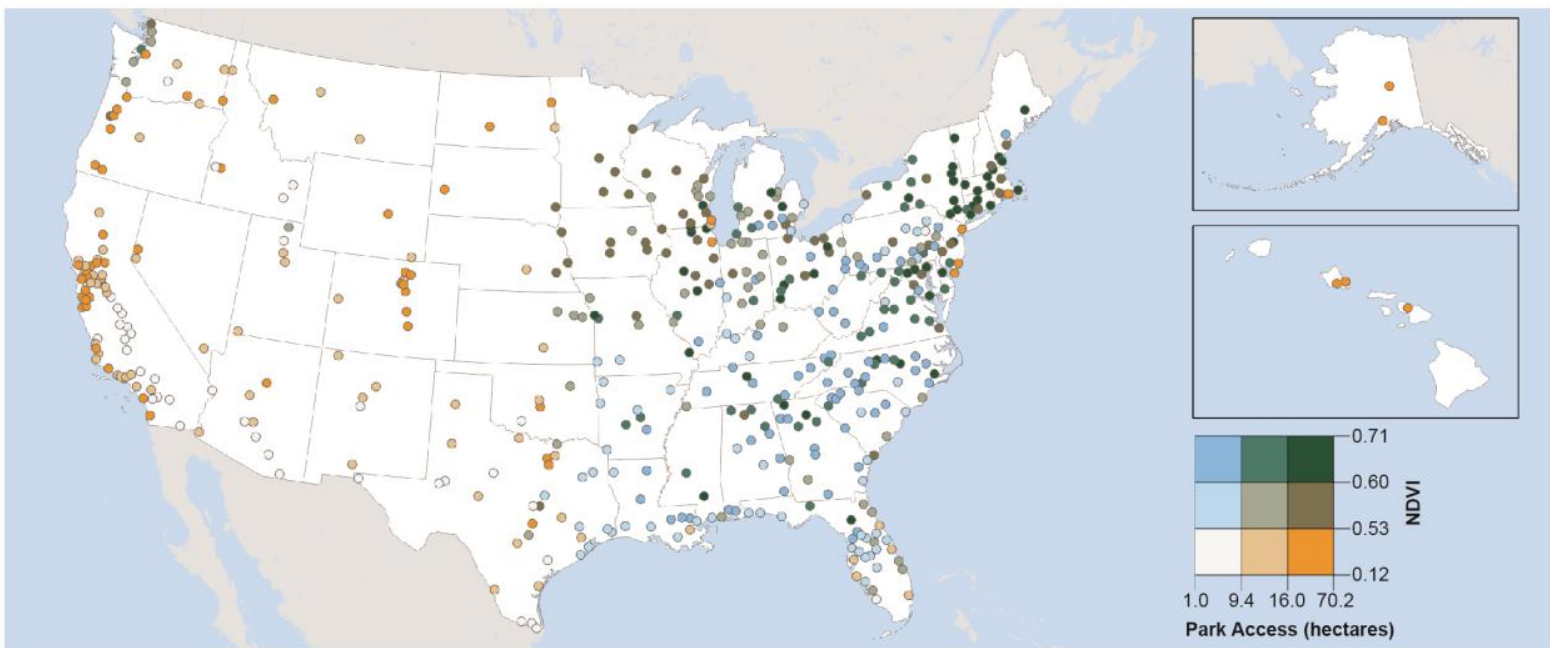

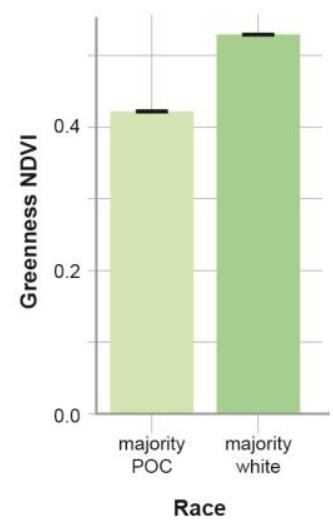

c

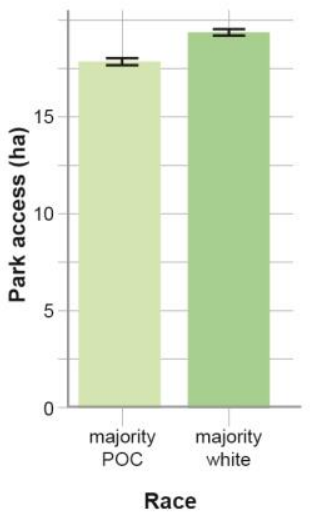

d

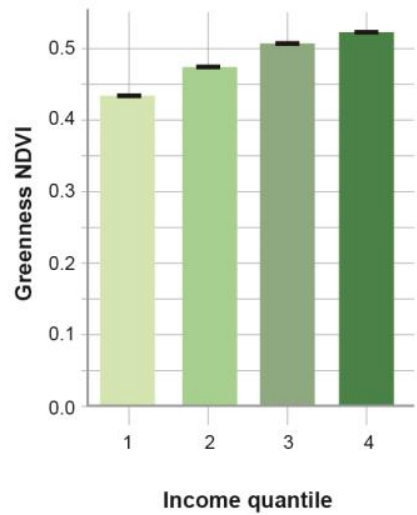

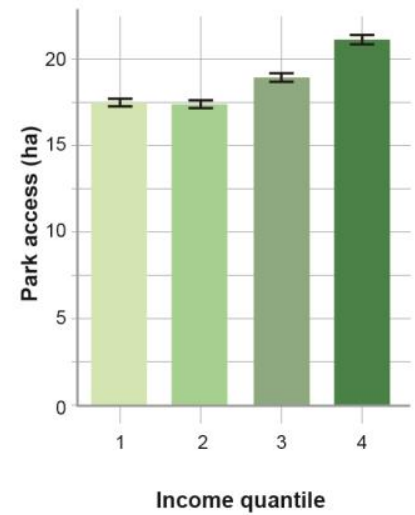

321 Fig. 3 | Nature access is inequitably distributed across urbanized areas in the US. a,

322 Greenness (NDVI) and park proximity (hectares) across all 486 urbanized areas in the US

323 (including 142,325 block groups). Urbanized areas are represented by a point, and values for

324 greenness and park proximity are within-urbanized area averages. b, Barchart of greenness

325 (NDVI), and $\mathbf{c}$, park proximity by race/ethnicity, showing higher greenness in white majority

326 block groups. d, Barchart of greenness (NDVI) and e, park proximity across all income

327 quantiles, showing higher greenness and more parks in block groups with higher income. Error

328 bars represent approximate $95 \%$ confidence intervals. 


\section{References}

330 1. McPhearson, T. et al. Pandemic injustice: Spatial and social distributions of COVID-19 in the 331 US Epicenter. in revision,.

332 2. Baena-Díez, J. M., Barroso, M., Cordeiro-Coelho, S. I., Díaz, J. L. \& Grau, M. Impact of 333 COVID-19 outbreak by income: hitting hardest the most deprived. J. Public Health 42, 698334703 (2020).

3. Cordes, J. \& Castro, M. C. Spatial analysis of COVID-19 clusters and contextual factors in New York City. Spat. Spatio-Temporal Epidemiol. 34, 100355 (2020).

4. Chen, J. T. \& Krieger, N. Revealing the Unequal Burden of COVID-19 by Income, Race/Ethnicity, and Household Crowding: US County Versus Zip Code Analyses. J. Public Health Manag. Pract. 27, S43 (2021).

5. Montenovo, L. et al. Determinants of disparities in covid-19 job losses. (2020).

6. Weill, J. A., Stigler, M., Deschenes, O. \& Springborn, M. R. Social distancing responses to COVID-19 emergency declarations strongly differentiated by income. Proc. Natl. Acad. Sci. 117, 19658-19660 (2020).

7. Brown, C. S. \& Ravallion, M. Inequality and the coronavirus: Socioeconomic covariates of 345 behavioral responses and viral outcomes across US counties. (2020).

346 8. Finch, W. H. \& Hernández Finch, M. E. Poverty and Covid-19: Rates of Incidence and 347 Deaths in the United States During the First 10 Weeks of the Pandemic. Front. Sociol. 5, 348 (2020).

349 9. Millett, G. A. et al. Assessing differential impacts of COVID-19 on Black communities. Ann. $350 \quad$ Epidemiol. (2020).

351 10. Astell-Burt, T., Feng, X., Mavoa, S., Badland, H. M. \& Giles-Corti, B. Do low-income 352 neighbourhoods have the least green space? A cross-sectional study of Australia's most 353 populous cities. BMC Public Health 14, 292 (2014). 
354 11. Gerrish, E. \& Watkins, S. L. The relationship between urban forests and income: A meta355 analysis. Landsc. Urban Plan. 170, 293-308 (2018).

356 12. Watkins, S. L. \& Gerrish, E. The relationship between urban forests and race: A meta357 analysis. J. Environ. Manage. 209, 152-168 (2018).

358 13. Nesbitt, L., Meitner, M. J., Girling, C., Sheppard, S. R. \& Lu, Y. Who has access to urban 359 vegetation? A spatial analysis of distributional green equity in 10 US cities. Landsc. Urban $360 \quad$ Plan. 181, 51-79 (2019).

361 14. Landry, S. M. \& Chakraborty, J. Street trees and equity: evaluating the spatial 362 distribution of an urban amenity. Environ. Plan. A 41, 2651-2670 (2009).

363 15. Zhou, X. \& Kim, J. Social disparities in tree canopy and park accessibility: A case study 364 of six cities in Illinois using GIS and remote sensing. Urban For. Urban Green. 12, 88-97 365 (2013).

366 16. Casey, J. A., James, P., Cushing, L., Jesdale, B. M. \& Morello-Frosch, R. Race, 367 ethnicity, income concentration and 10-year change in urban greenness in the United States. 368 Int. J. Environ. Res. Public. Health 14, 1546 (2017).

369 17. Klompmaker, J. O. et al. County-level exposures to greenness and associations with 370 COVID-19 incidence and mortality in the United States. medRxiv 2020.08.26.20181644 $371 \quad$ (2020) doi:10.1101/2020.08.26.20181644.

372 18. Soga, M., Evans, M. J., Tsuchiya, K. \& Fukano, Y. A room with a green view: the 373 importance of nearby nature for mental health during the COVID-19 pandemic. Ecol. Appl. $374 \quad \mathbf{n} / \mathbf{a}$, e2248.

375 19. Lopez, B., Kennedy, C. \& McPhearson, T. Parks are Critical Urban Infrastructure:

376 Perception and Use of Urban Green Spaces in NYC During COVID-19. (2020).

377 20. Ugolini, F. et al. Effects of the COVID-19 pandemic on the use and perceptions of urban 378 green space: An international exploratory study. 10 (2020). 
379 21. Bratman, G. N., Hamilton, J. \& Daily, G. The impacts of nature experience on human 380 cognitive function and mental health. Ann. N. Y. Acad. Sci. 1249, 118-136 (2012).

381 22. Kuo, M. How might contact with nature promote human health? Promising mechanisms 382 and a possible central pathway. Front. Psychol. 6, 1093 (2015).

383 23. Kondo, M. C., Fluehr, J. M., McKeon, T. \& Branas, C. C. Urban green space and its 384 impact on human health. Int. J. Environ. Res. Public. Health 15, 445 (2018).

385 24. Lodoen, M. B. \& Lanier, L. L. Natural killer cells as an initial defense against pathogens. $386 \quad$ Curr. Opin. Immunol. 18, 391-398 (2006).

387 25. Vivier, E., Tomasello, E., Baratin, M., Walzer, T. \& Ugolini, S. Functions of natural killer 388 cells. Nat. Immunol. 9, 503-510 (2008).

38926 . Li, Q. Effect of forest bathing trips on human immune function. Environ. Health Prev. $390 \quad$ Med. 15, 9-17 (2010).

391 27. Bratman, G. N. et al. Nature and mental health: An ecosystem service perspective. Sci. $392 \quad A d v .5$, eaax0903 (2019).

393 28. McDonald, R. I., Beatley, T. \& Elmqvist, T. The green soul of the concrete jungle: The 394 urban century, the urban psychological penalty, and the role of nature. Sustain. Earth 1, 3 395 (2018).

396 29. Spotswood, E. N. et al. The Biological Deserts Fallacy: Cities in Their Landscapes 397 Contribute More than We Think to Regional Biodiversity. BioScience (2021).

398 30. Venter, Z. S., Shackleton, C. M., Van Staden, F., Selomane, O. \& Masterson, V. A. 399 Green Apartheid: Urban green infrastructure remains unequally distributed across income 400 and race geographies in South Africa. Landsc. Urban Plan. 203, 103889 (2020).

401 31. Wüstemann, H., Kalisch, D. \& Kolbe, J. Access to urban green space and environmental 402 inequalities in Germany. Landsc. Urban Plan. 164, 124-131 (2017).

403 32. James, P., Hart, J. E., Banay, R. F. \& Laden, F. Exposure to greenness and mortality in 404 a nationwide prospective cohort study of women. (2016). 
33. Hystad, P. et al. Residential greenness and birth outcomes: evaluating the influence of spatially correlated built-environment factors. Environ. Health Perspect. 122, 1095-1102 (2014).

34. Orban, E., Sutcliffe, R., Dragano, N., Jöckel, K.-H. \& Moebus, S. Residential surrounding greenness, self-rated health and interrelations with aspects of neighborhood environment and social relations. J. Urban Health 94, 158-169 (2017).

35. Almanza, E., Jerrett, M., Dunton, G., Seto, E. \& Pentz, M. A. A study of community design, greenness, and physical activity in children using satellite, GPS and accelerometer data. Health Place 18, 46-54 (2012).

36. McEachan, R. R. C. et al. The association between green space and depressive symptoms in pregnant women: moderating roles of socioeconomic status and physical activity. J Epidemiol Community Health 70, 253-259 (2016).

37. Akpinar, A. How is quality of urban green spaces associated with physical activity and health? Urban For. Urban Green. 16, 76-83 (2016).

38. Brown, G., Schebella, M. F. \& Weber, D. Using participatory GIS to measure physical activity and urban park benefits. Landsc. Urban Plan. 121, 34-44 (2014).

39. Paquet, C. et al. Are accessibility and characteristics of public open spaces associated with a better cardiometabolic health? Landsc. Urban Plan. 118, 70-78 (2013).

40. Grubesic, T. H. Zip codes and spatial analysis: Problems and prospects. Socioecon. Plann. Sci. 42, 129-149 (2008).

41. The New York Times. Coronavirus US Cases Database.

426 https://www.nytimes.com/interactive/2020/us/coronavirus-us-cases.html (accessed Oct 1, 427 2020).

428 42. Trabucco, A. \& Zomer, R. Global Aridity Index (Global-Aridity) and Global Potential 429 Evapo-Transpiration (Global-PET) Geospatial Database. (CGIAR Consortium for Spatial 430 Information, 2009). 
431 43. Parks on the clock: why we believe in the 10-minute walk. The Trust for Public Land 432 https://www.tpl.org/blog/why-the-10-minute-walk.

433 44. Sallis, J. F., Millstein, R. A. \& Carlson, J. A. Community design for physical activity. in $434 \quad$ Making Healthy Places 33-49 (Springer, 2011).

435 45. United States Census Bureau. American Community Survey 5-Year 2018.

436 46. R Development Core Team. R: A Language and Environment for Statistical Computing. 437 in R Foundation for Statistical Computing (Available at: http://www.R-project.org, 2015).

438 47. Bivand, R. S. \& Wong, D. W. S. Comparing implementations of global and local 439 indicators of spatial association. TEST 27, 716-748 (2018).

440 48. Bates, D., Mächler, M., Bolker, B. \& Walker, S. Fitting Linear Mixed-Effects Models $441 \quad$ Using Ime4. J. Stat. Softw. 67, (2015).

442 49. Bolker, B. M. et al. Generalized linear mixed models: a practical guide for ecology and 443 evolution. Trends Ecol. Evol. 24, 127-135 (2009).

444 50. Hilbe, J. M. Negative Binomial Regression. (Cambridge University Press, 2011).

445 51. Beale, C. M., Lennon, J. J., Yearsley, J. M., Brewer, M. J. \& Elston, D. A. Regression 446 analysis of spatial data. Ecol. Lett. 13, 246-264 (2010).

447 52. Kissling, W. D. \& Carl, G. Spatial autocorrelation and the selection of simultaneous 448 autoregressive models. Glob. Ecol. Biogeogr. 17, 59-71 (2008). 


\section{Figures}

a

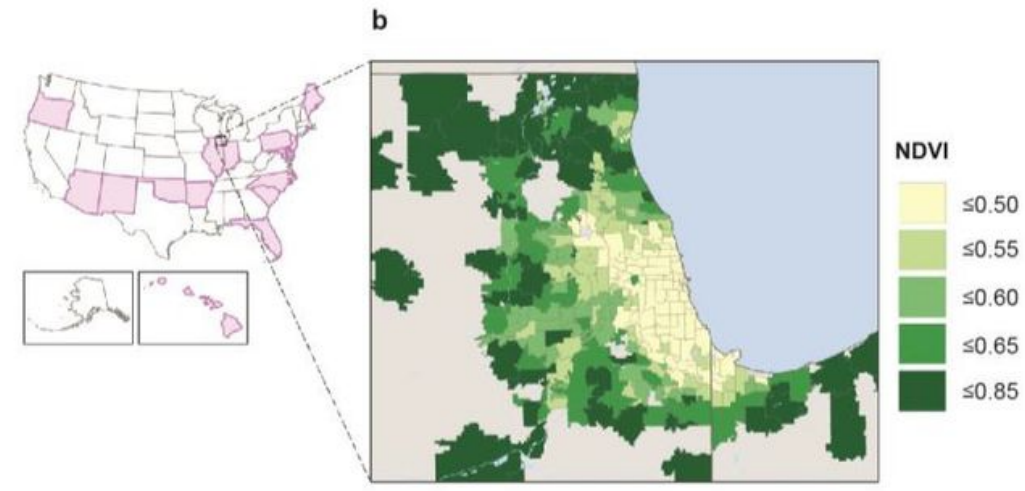

d

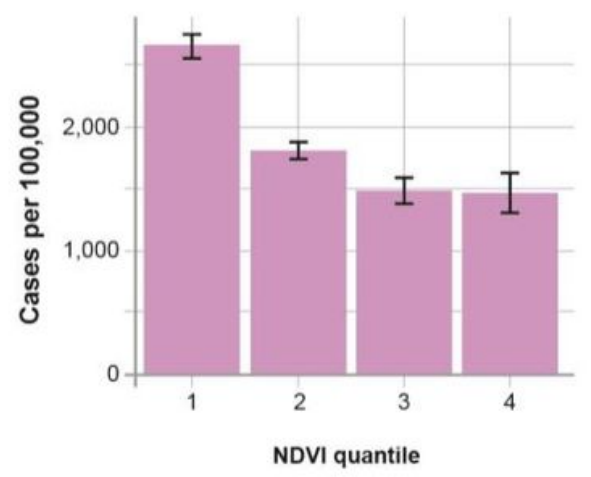

e

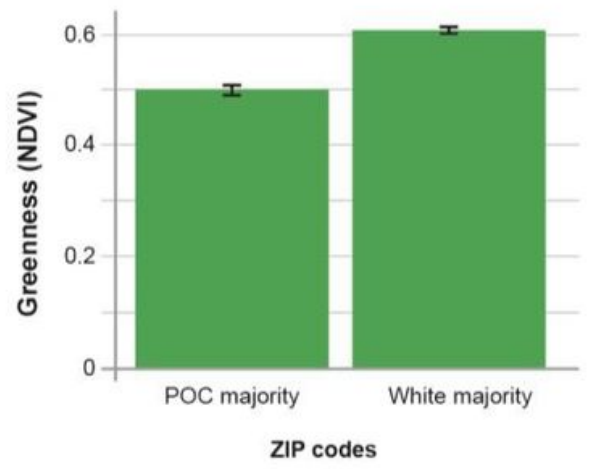

c

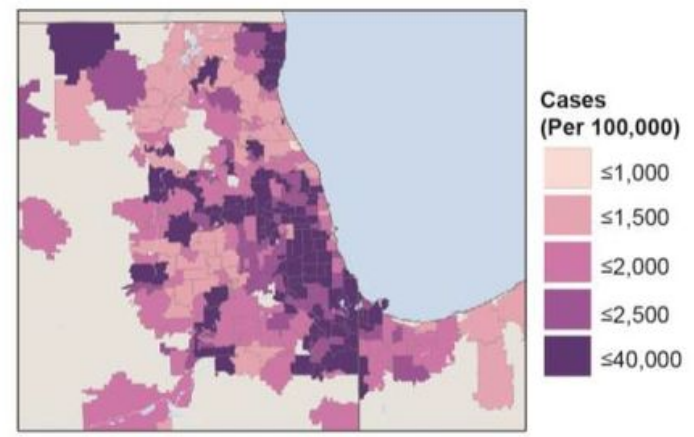

f

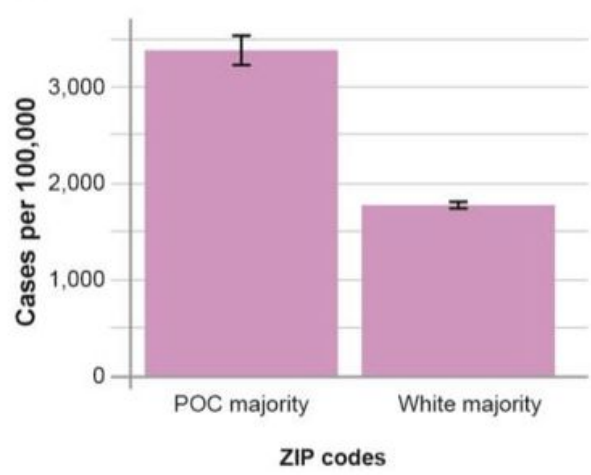

\section{Figure 1}

COVID-19 case rates are related to both greenness and race/ethnicity. a, This analysis used reported COVID-19 cases at the ZIP Code scale from 17 states. b, Average NDVI values and c, COVID-19 case rates per 100,000 people across ZIP Codes around Chicago, IL, as an example. d, Barchart of greenness (NDVI) represented as quantiles and rates of COVID-19 showing a decline in cases with higher NDVI. e, Barchart of greenness showing higher greenness in white majority ZIP Codes. f, COVID-19 case rates (per $100,000)$ showing lower rates of cases in majority white ZIP codes. Error bars represent approximate $95 \%$ confidence intervals. 


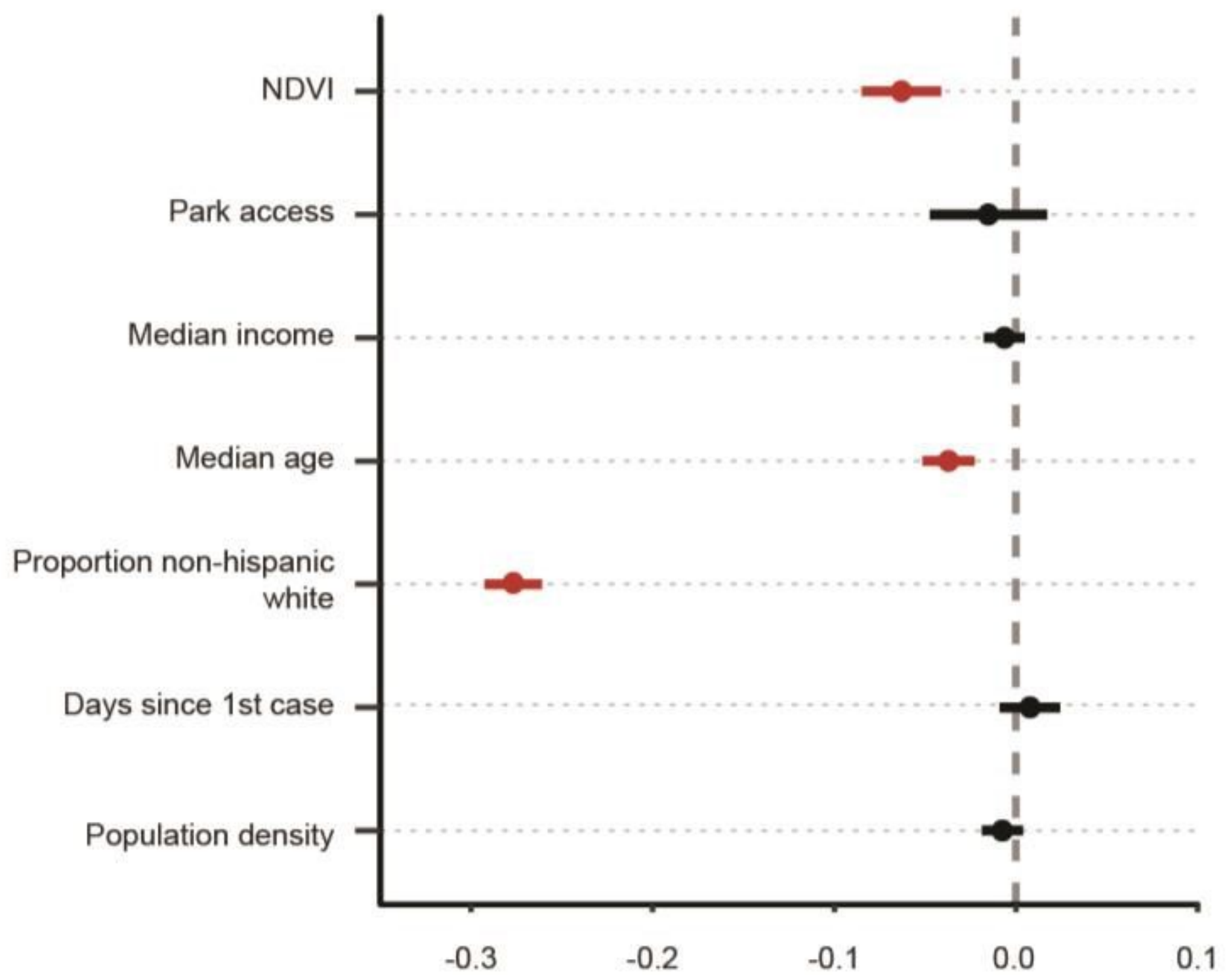

Covid-19 cases coefficient value

\section{Figure 2}

Greener ZIP Codes have fewer COVID-19 cases after accounting for other factors. Coefficient values represent effect sizes from a negative binomial mixed effects model for the relationship between rates of COVID-19 (cases/100,000 people) and greenness (NDVI), park access (ha), median income, median age, proportion persons of color, days since the first case (county-scale), and population density. Coefficient values are represented as dots, bars represent $95 \%$ confidence intervals, and significant variables are shown in red. 


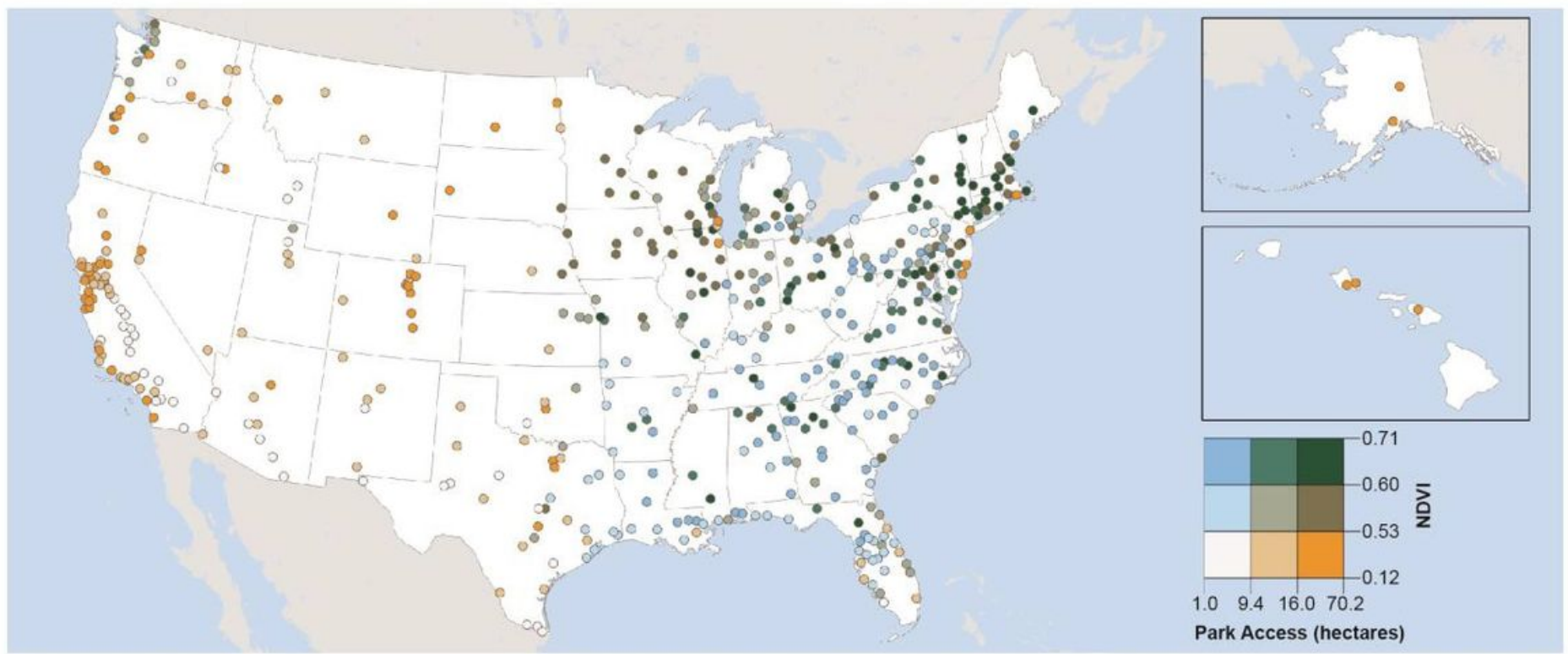

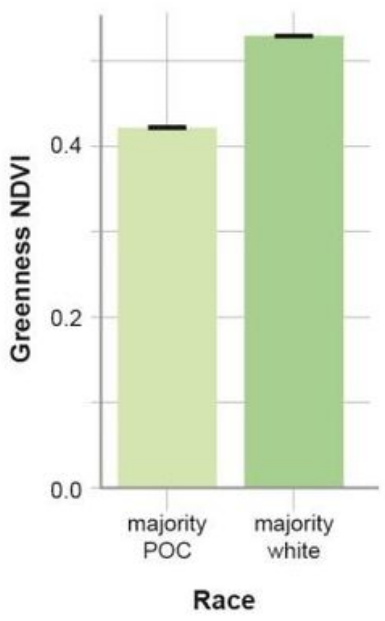

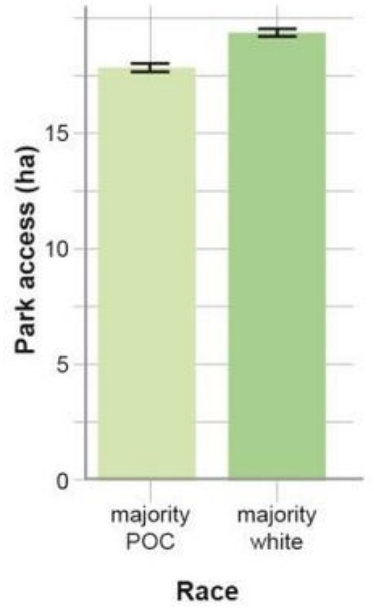

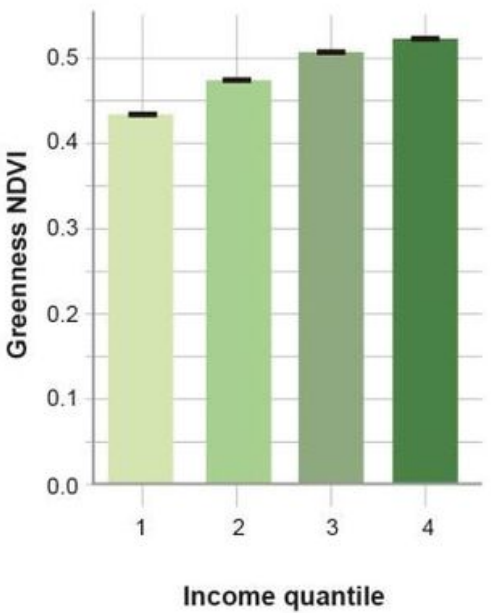

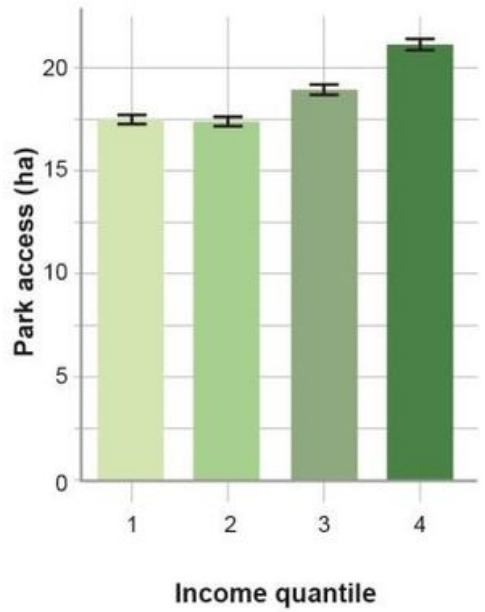

\section{Figure 3}

Nature access is inequitably distributed across urbanized areas in the US. a, Greenness (NDVI) and park proximity (hectares) across all 486 urbanized areas in the US (including 142,325 block groups). Urbanized areas are represented by a point, and values for greenness and park proximity are withinurbanized area averages. b, Barchart of greenness (NDVI), and c, park proximity by race/ethnicity, showing higher greenness in white majority block groups. d, Barchart of greenness (NDVI) and e, park proximity across all income quantiles, showing higher greenness and more parks in block groups with higher income. Error bars represent approximate $95 \%$ confidence intervals.

\section{Supplementary Files}


This is a list of supplementary files associated with this preprint. Click to download.

- SpotswoodNatureSustainabilitySUPPLEMENTARYMATERIALS.pdf 